\title{
Cognitive assessments for the early diagnosis of dementia after stroke
}

\author{
This article was published in the following Dove Press journal: \\ Neuropsychiatric Disease and Treatment \\ 12 September 2014 \\ Number of times this article has been viewed
}

\author{
Noor Kamal Al-Qazzaz ${ }^{1,2}$ \\ Sawal Hamid Ali' \\ Siti Anom Ahmad ${ }^{3}$ \\ Shabiul Islam ${ }^{4}$ \\ 'Department of Electrical, Electronic \\ and Systems Engineering, Faculty of \\ Engineering and Built Environment, \\ Universiti Kebangsaan Malaysia (UKM), \\ Bangi, Selangor, Malaysia; ${ }^{2}$ Department \\ of Biomedical Engineering, \\ Al-Khwarizmi College of Engineering, \\ Baghdad University, Baghdad, Iraq; \\ ${ }^{3}$ Department of Electrical and \\ Electronic Engineering, Faculty of \\ Engineering, Universiti Putra Malaysia \\ (UPM), Serdang, Selangor, Malaysia; \\ ${ }^{4}$ Institute of Microengineering and \\ Nanoelectronics (IMEN), UKM, Bangi, \\ Selangor, Malaysia
}

\begin{abstract}
The early detection of poststroke dementia (PSD) is important for medical practitioners to customize patient treatment programs based on cognitive consequences and disease severity progression. The aim is to diagnose and detect brain degenerative disorders as early as possible to help stroke survivors obtain early treatment benefits before significant mental impairment occurs. Neuropsychological assessments are widely used to assess cognitive decline following a stroke diagnosis. This study reviews the function of the available neuropsychological assessments in the early detection of PSD, particularly vascular dementia (VaD). The review starts from cognitive impairment and dementia prevalence, followed by PSD types and the cognitive spectrum. Finally, the most usable neuropsychological assessments to detect VaD were identified. This study was performed through a PubMed and ScienceDirect database search spanning the last 10 years with the following keywords: "post-stroke"; "dementia"; "neuropsychological"; and "assessments". This study focuses on assessing VaD patients on the basis of their stroke risk factors and cognitive function within the first 3 months after stroke onset. The search strategy yielded 535 articles. After application of inclusion and exclusion criteria, only five articles were considered. A manual search was performed and yielded 14 articles. Twelve articles were included in the study design and seven articles were associated with early dementia detection. This review may provide a means to identify the role of neuropsychological assessments as early PSD detection tests.
\end{abstract}

Keywords: poststroke dementia, vascular dementia, neuropsychological assessments, early dementia detection

\section{Introduction}

Stroke, a cerebrovascular disease (CVD), is one of the major causes of quality of life reduction through physical disabilities; the second most important risk factor for cognitive impairment and dementia, with a frequency ranging from $16 \%-32 \%$; and the third cause of mortality after heart diseases and cancer. ${ }^{1,2}$ However, aging and possession of a specific form of gene that links mild cognitive impairment (MCI) to Alzheimer's disease (AD) are the most common causes of significant cognitive impairment. ${ }^{3}$ Poststroke dementia (PSD) includes all dementia types that may occur after stroke. Stroke survivors more prone to develop dementia, of which $20 \%-25 \%$ are diagnosed with vascular dementia ( $\mathrm{VaD}$ ), approximately $30 \%$ with degenerative dementia (particularly AD), and 10\%-15\% with a combination of AD and VaD (mixed dementia). ${ }^{4-6}$ Approximately $1 \%-4 \%$ of elderly people aged 65 years suffer from $\mathrm{VaD}$, and the prevalence doubles every $5-10$ years after this age. ${ }^{5,7}$ However, cognitive impairment and dementia following a stroke diagnosis may involve multiple functions, and the most affected domains are attention, executive function, memory, visuospatial ability, and language, as shown in Table 1.,8,9
Correspondence: Noor Kamal Al-Qazzaz Department of Electrical, Electronic and Systems Engineering, Faculty of Engineering and Built Environment, Universiti Kebangsaan Malaysia, UKM, Bangi, Selangor 43600, Malaysia Email noorbmemsc@siswa.ukm.edu.my submit your manuscript | www.dovepress.com

Dovepress

http://dx.doi.org/1 0.2147/NDT.S68443
Neuropsychiatric Disease and Treatment 2014:10 1743-175। 1743

(c) (i) (5) 2014 Al-Qazzaz et al. This work is published by Dove Medical Press Limited, and licensed under Creative Commons Attribution - Non Commercial (unported, v3.0) License. The full terms of the License are available at http://creativecommons.org/licenses/by-nc/3.0/. Non-commercial uses of the work are permitted without any further permission from Dove Medical Press Limited, provided the work is properly attributed. Permissions beyond the scope of the License are administered by Dove Medical Press Limited. Information on how to request permission may be found at: http://www.dovepress.com/permissions.php 
Table I Cognition domain and function

\begin{tabular}{ll}
\hline Domain & Function related to domain \\
\hline Attention & $\begin{array}{l}\text { Focusing, sustain, selective, alternative, divided, } \\
\text { shifting }\end{array}$ \\
Executive function & $\begin{array}{l}\text { Planning, organizing thoughts, inhibition, control } \\
\text { Recall and recognition of visual and verbal } \\
\text { Memory }\end{array}$ \\
information \\
Visuospatial ability & $\begin{array}{l}\text { Visual search, drawing, concentration } \\
\text { Language }\end{array}$ \\
& Expressive (Broca's aphasia), receptive \\
& (Wernicke's aphasia) \\
\hline
\end{tabular}

$\mathrm{VaD}$ is the second most common type of dementia after $\mathrm{AD}$ and is considered to be the primary cause of clinical deficits with burden on cognition in vascular cognitive impairment (VCI) resulting from CVD and ischemic or hemorrhagic brain injury. ${ }^{10,11} \mathrm{VCI}$ describes the $\mathrm{VaD}$ cognitive spectrum in the cognitive domain starting from MCI and ending with severe dementia. The VCI spectrum is defined after the point where the brain's cognitive function remains intact; at risk, this period is called cognitive impairment no dementia. ${ }^{12-15}$ MCI in cognitive function is greater than expected with respect to the age and education level of patients, but it is unrelated to daily life activities. ${ }^{8,14}$ Clinically, MCI is the transitional stage between early normal cognition and late severe dementia, and patients with MCI exhibit a high potential to develop dementia. ${ }^{5,16}$ The most frequently observed symptoms of MCI are limited to memory retrieval; however, the daily life activities are unaffected. ${ }^{17}$ The stage after MCI, which is termed the dementia stage, will reduce long-term memory (particularly episodic memory) and will eventually result in executive function impairment. ${ }^{18-20} \mathrm{VaD}$ or severe dementia is the endpoint of the VCI spectrum that affects $10 \%$ of single-attack stroke patients in the subsequent months after ischemic stroke onset and 30\% after recurrent ischemic stroke. ${ }^{21}$ Figure 1 shows the cognitive consequences that predispose stroke individuals in the VCI spectrum.

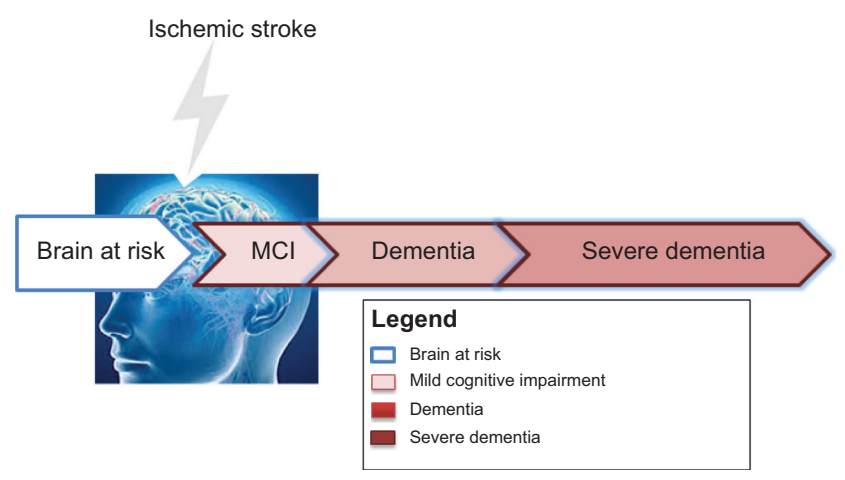

Figure I VCl spectrum and dementia.

Abbreviations: $\mathrm{VCl}$, vascular cognitive impairment; $\mathrm{MCl}$, mild cognitive impairment.
Poststroke cognitive impairment patterns change considerably during the whole VCI spectrum. Thus, the cognitive defects following a stroke may be mapped by assessing the cognitive domain. However, poststroke prominent impairments are associated with one or more cognitive functions and thus require the evaluation of the decline in cognitive function, including attention, memory, language, and orientation. ${ }^{1}$ The neuropsychological assessments that are currently available for cognitive impairment and dementia have been developed by the National Institute of Neurological Disorders and Stroke and Association Internationale pour la Recherché et l'Enseignement en Neurosciences (NINDS-AIREN) for $\mathrm{VaD} .{ }^{22}$ In clinical practice, the most usable test to evaluate the severity of dementia (but not limited to this condition) is to run the diagnosis based on the Diagnostic and Statistical Manual of Mental Disorders, Fourth Edition (DSM-IV) ${ }^{23}$ Mini-Mental State Examination (MMSE) ${ }^{24}$ Montreal Cognitive Assessment (MoCA), ${ }^{25}$ and Addenbrooke's Cognitive Examination Revised (ACE-R). ${ }^{26-29}$ The severity of cognitive symptoms could be assessed using the Clinical Dementia Rating (CDR ${ }^{30}$ and Geriatric Depression Scale (GDS) ${ }^{31}$ These neuropsychological assessments have been used to assess different cognitive functions to promote neuropsychological diagnosis and the understanding of cognitive impairment following a stroke diagnosis.

This review will focus on $\mathrm{VaD}$ as a common cause of PSD. This work aims to identify the risk factors for cognitive impairment and the effect of such factors on cognitive function. A secondary aim is to assess various neuropsychological assessments used for the early detection of dementia in stroke patients.

\section{Methods}

Studies have been performed for PubMed and ScienceDirect. Articles were dated from 2003-2014. The search was based on the following keywords: "post-stroke"; "dementia"; "neuropsychological"; and "assessments". Figure 2 shows the three steps that were used to select eligible articles. In step 1, the search was limited to English-language and case-control or cohort studies with patients aged 50 years and above and excluded the articles found to be related to brain injury, kidney or pulmonary diseases, heart bypass surgery, aortic valve implementation, and left ventricle assist devices. In addition to the articles related to AD and psychiatric diseases or other dementia types, systematic review, pilot studies, and meta-analysis papers were the primary articles found in this search. Step 2 was based on the following three diagnostic criteria: 1) patient risk factors associated with PSD; 2) description and information 

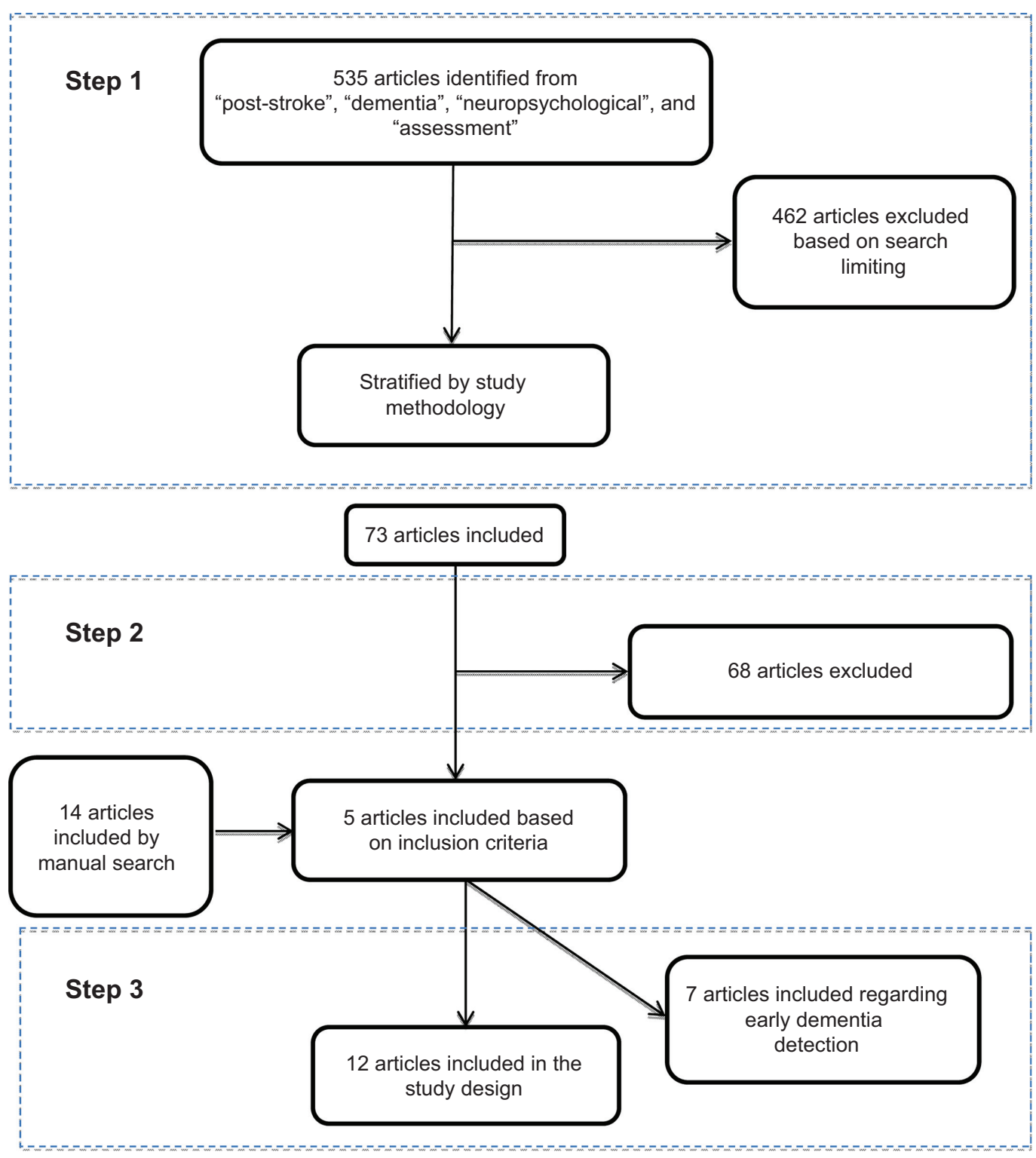

Figure 2 Flowchart of the literature search and selection process.

about the poststroke cognitive impairment/dysfunction in cognitive function among survivors that had been tested by neuropsychological assessments and evaluated using DSM or other dementia evaluation scales; and 3) PSD evaluation that started from a baseline of first stroke up to 3 months poststroke using neuropsychological assessments. In step 3, due to the limitations imposed by the previous search that focused on the first 3 months after stroke, a manual search of the cited references for related articles identified additional related articles for this research.

\section{Results}

Initially, the literature search yielded 535 articles. After applying the search criteria (as in step 1), the number of relevant articles decreased to 73. Step 2 reduced the number of relevant articles to five, and with the manual search, an additional 14 articles were included to yield 19 articles for review.

\section{Association between risk factors and cognitive impairment}

Table 2 shows an overview of the demographic and clinical characteristics of patients on the basis of dementia severity. The relationship between individual risk factors and poststroke VaD development are shown. Several risk factors such as CVD, hypertension, heart disease, and hyperlipidemia, are associated with stroke and $\mathrm{VaD}$ development. ${ }^{32}$ Diabetes mellitus was another risk factor that was highly associated 


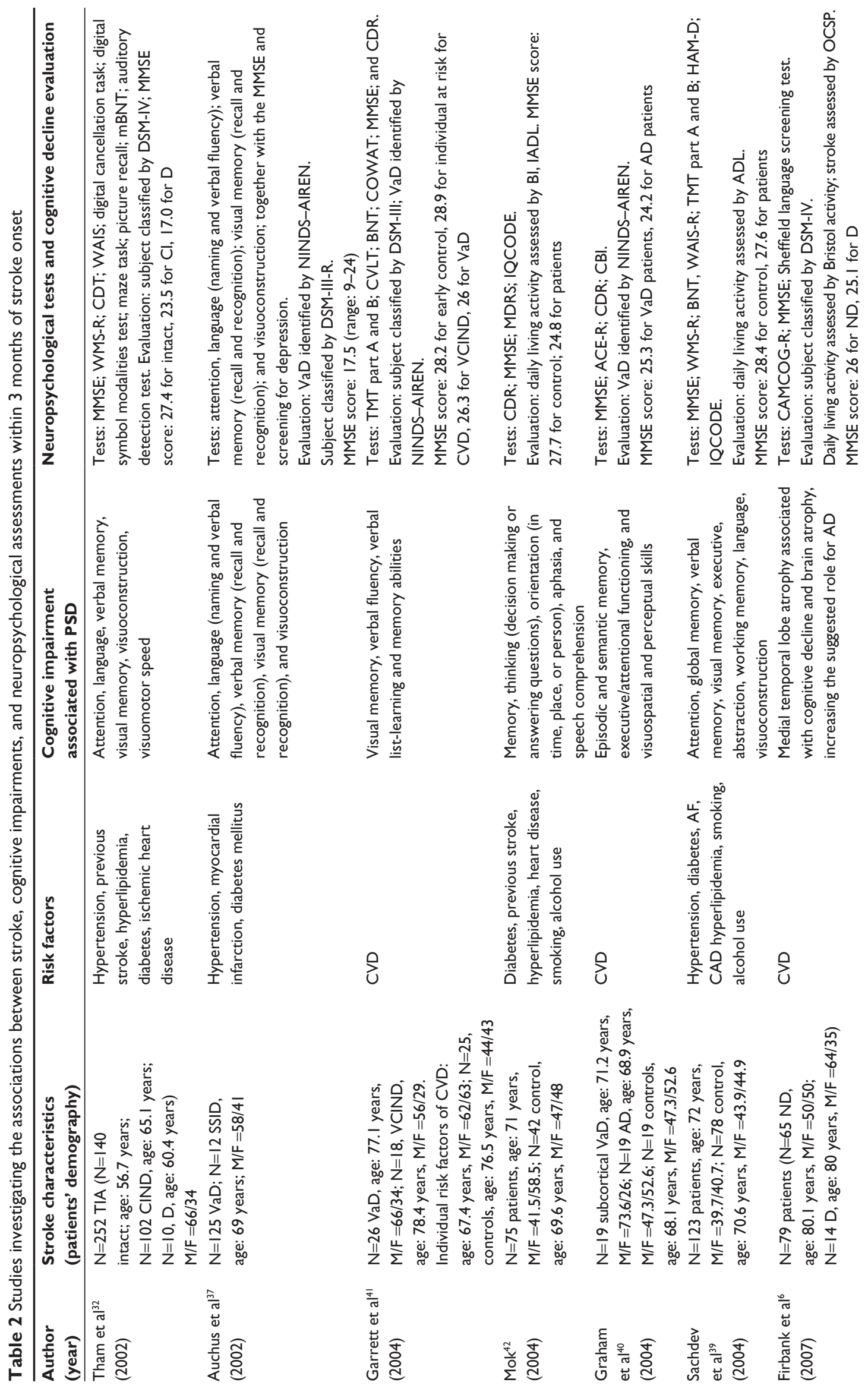




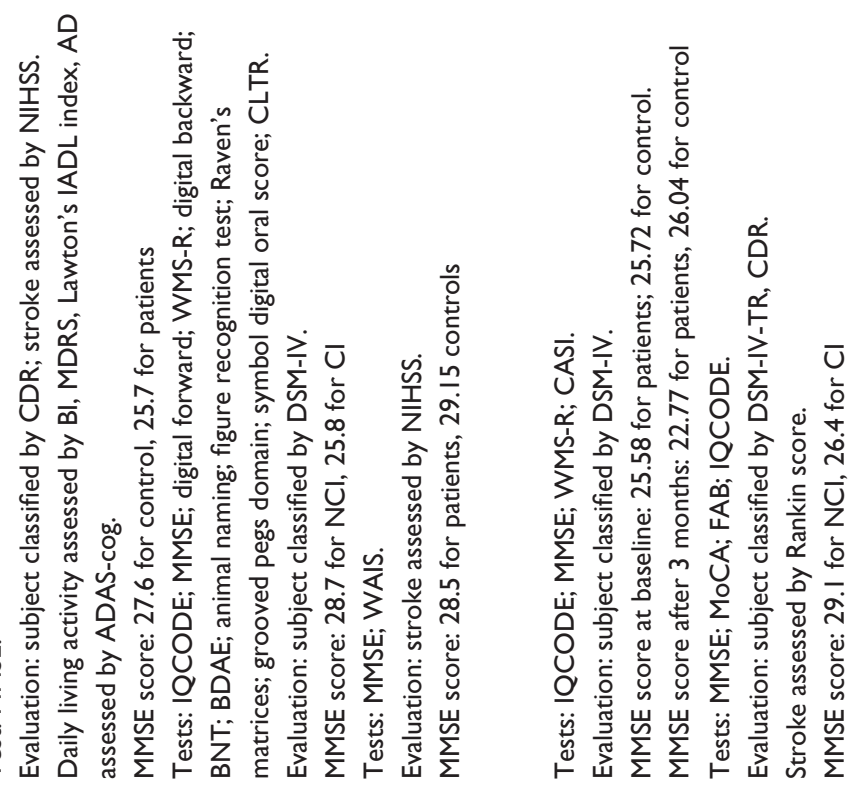

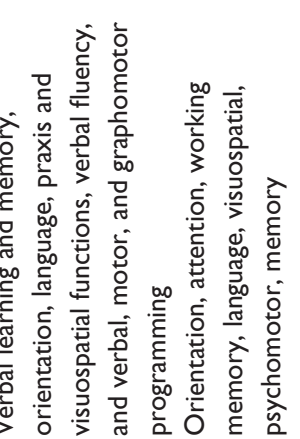
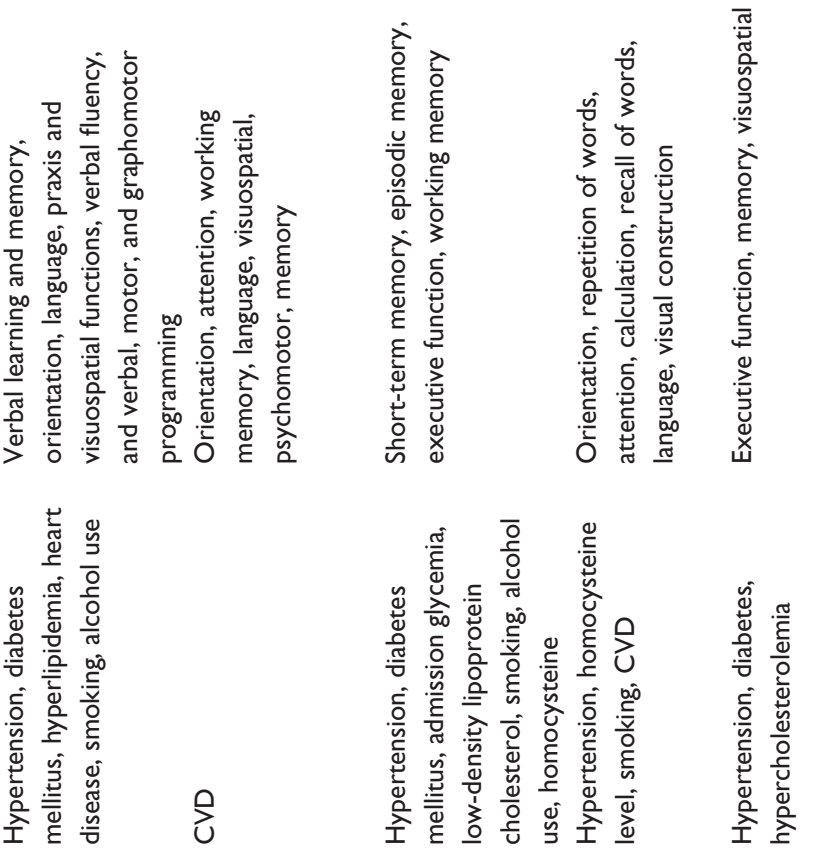

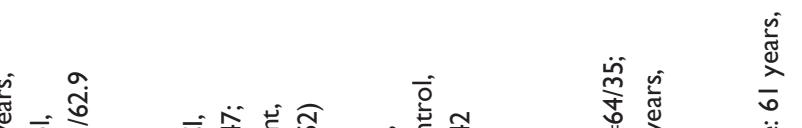

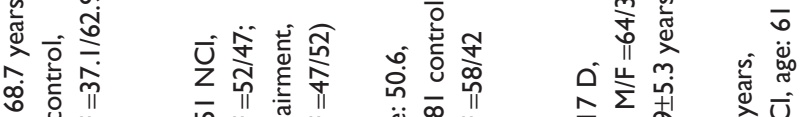

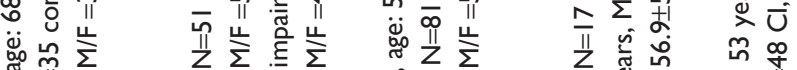

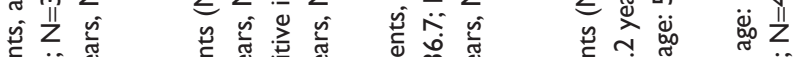

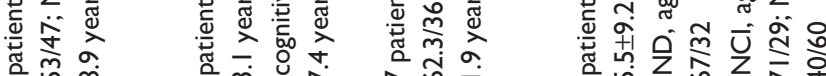

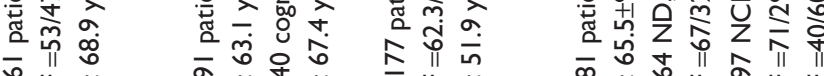

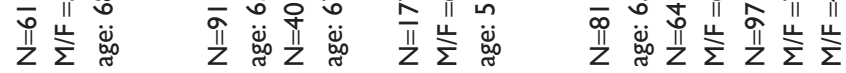

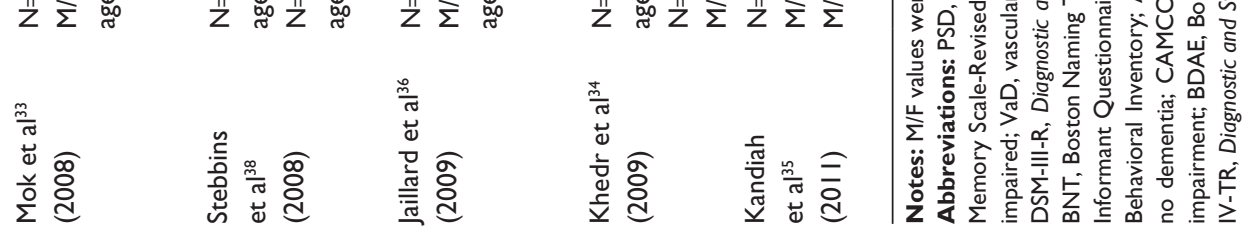

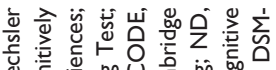

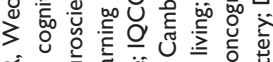

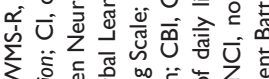

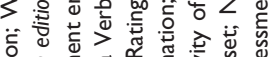

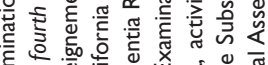

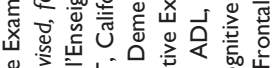

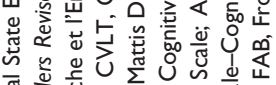

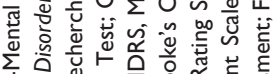

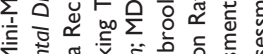

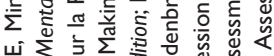

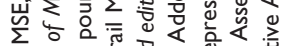

है

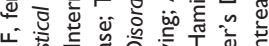

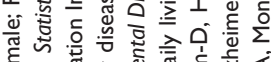

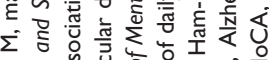

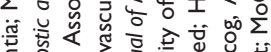

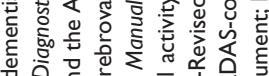

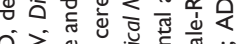

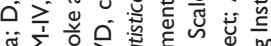

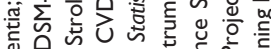

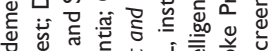

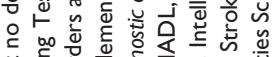

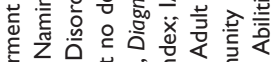

施

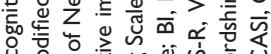

$\circlearrowleft$ O

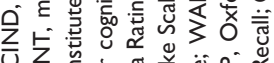

U

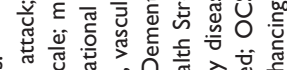

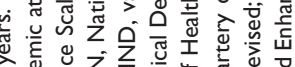

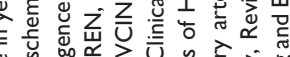

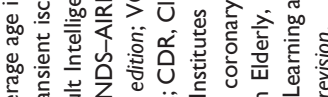

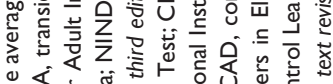

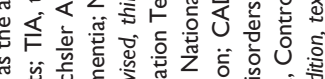

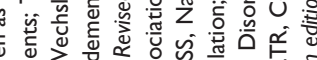

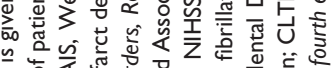

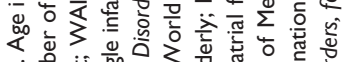

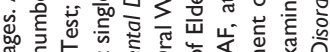

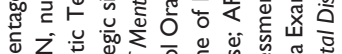

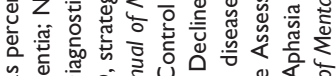

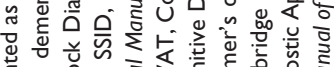

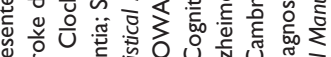

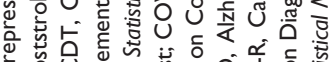

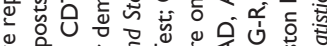

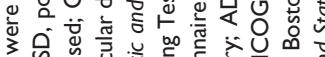

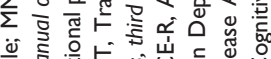

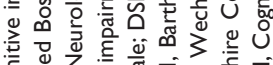


with $\mathrm{VaD}$ development. Other factors were cigarette smoking and alcohol intake.

Demographic determinants, such as age and sex (shown in Table 2), are nonmodifiable risk factors for stroke patients. Compared to the control subjects, the risk of dementia was higher with age and may have resulted in $\mathrm{VaD}$. Age was also correlated with a diagnosis of vascular diseases. However, no significant relationship was observed between dementia development and patient sex.

Table 2 also shows that CVD was the major risk factor for cognitive impairment and $\mathrm{VaD}$ following stroke onset. Modifiable risk factors such as hypertension, heart disease, and diabetes mellitus were the highest risk factors for stroke and dementia, followed by other factors that might predispose subjects to stroke and even VaD. ${ }^{33-38}$ Moreover, an association between a risk factor and the decline or even loss of one or more cognitive functions (for instance, attention and executive function) were significantly impaired in the studies referenced..$^{33,35-41}$ This was followed by short-term memory, working memory, and verbal and visual memories, which were significantly impaired in all studies. The decline in cognitive functions was assessed using neuropsychological assessments such as the MMSE, MoCA, ACE-R, and other assessments within the third month of stroke onset.

Focusing on the MMSE score to differentiate dementia severity among patients provided a clear picture of the decreasing trend of the score among stroke patients. Patients were evaluated for $\mathrm{VaD}$ using NINDS-AIREN, and the subjects were classified using the DSM-IV or daily living activity assessments.

\section{Function of neuropsychological assessments in the early diagnosis of poststroke $\mathrm{VaD}$}

Within the VCI spectrum that ranges from MCI to $\mathrm{VaD}$, efforts have been made to assess patients in the early dementia stage to predict optimal medical treatment for patients. Table 2 shows that at the early stage (MCI), attention and executive function were affected, which was later followed by the loss of other functions in the memory domain.

Table 3 shows the poststroke VaD that occurred within the first 3 months of the first stroke onset. All studies used one or more dementia evaluation assessments, such as the DSMIII or DSM-IV, CDR and Mattis Dementia Rating Scale. All studies used the MMSE, in addition to other neuropsychological assessments, to assess patients after stroke diagnosis and dementia evaluation. The evaluation score of MMSE for normal individuals was above 24 , but Table 2 shows that the MMSE score for stroke patients ranged from 17-28. This result indicates that the MMSE cannot accurately measure the cognitive impairment of poststroke patients. MMSE is

Table 3 Studies presenting the limitations in poststroke memory assessment

\begin{tabular}{|c|c|c|}
\hline Study/year & Stroke characteristics of patients & Neuropsychological tests \\
\hline $\begin{array}{l}\text { Cao et } a^{44} \\
(2007)\end{array}$ & $\begin{array}{l}\mathrm{N}=40 \text { patients, age: } 37.8 \text { years, } M / \mathrm{F}=37 / 62 ; \mathrm{N}=40 \text { control, } \\
\text { age: } 38.8 \text { years, } M / \mathrm{F}=40 / 60\end{array}$ & $\begin{array}{l}\text { MMSE, AVLT, DST, Token test, linguistic tasks, SVF, } \\
\text { BNT, Cori's block-tapping board, similarities, RPM, SDS }\end{array}$ \\
\hline $\begin{array}{l}\text { Yoshida et al }{ }^{45} \\
(2011)\end{array}$ & 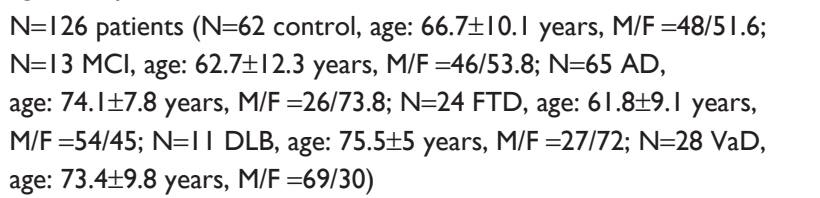 & ACE, MMSE, CDR \\
\hline $\begin{array}{l}\text { Bour et } \mathrm{al}^{43} \\
(2010)\end{array}$ & $\mathrm{N}=194$ patients, age: 68.3 years, $M / \mathrm{F}=55.2 / 44.8$ & MMSE, MAAS, CAMCOG, GIT, SCWT, CST, AVLT \\
\hline $\begin{array}{l}\text { Dong et al }{ }^{47} \\
(2010)\end{array}$ & $\mathrm{N}=100$ patients, age: $61.2 \pm 11.3$ years, $M / F=62 / 38$ & MMSE, MoCA, IQCODE \\
\hline $\begin{array}{l}\text { Pendlebury }{ }^{49} \\
(2012)\end{array}$ & $\mathrm{N}=91 \mathrm{ND}$ patients, age: 73.4 years, $\mathrm{M} / \mathrm{F}=56 / 44 ; \mathrm{N}=39 \mathrm{MCl}$ patients & $\begin{array}{l}\text { MoCA, ACE-R, MMSE, TMT parts A and B, SDMT, BNT, } \\
\text { Rey-Osterrieth complex figure, HVLT, GDS }\end{array}$ \\
\hline $\begin{array}{l}\text { Sikaroodi et a }\left.\right|^{48} \\
(2012)\end{array}$ & $\mathrm{N}=50$ patients, age: $51.8 \pm 13.18$ years, $M / F=32 / 68$ & MMSE, MoCA \\
\hline $\begin{array}{l}\text { Raimondi et a }\left.\right|^{46} \\
(2012)\end{array}$ & $\begin{array}{l}N=83 \text { patients }(N=26 \text { control, age: } 73.23 \text { years, } M / F=50 / 50 ; N=25 A D \text {, } \\
\text { age: } 77.64 \text { years, } M / F=40 / 60 ; N=32 \mathrm{VaD} \text {, age: } 75.59 \text { years, } M / F=50 / 50)\end{array}$ & CDR, BDI-II, MMSE, ACE-R \\
\hline
\end{tabular}

Notes: $M / F$ values were represented as percentages. Age is given as the average age in years.

Abbreviations: N, number of patients; M, male; F, female; MMSE, Mini-Mental State Examination; AVLT, Auditory-Verbal Learning Test; DST, Digital Span Test; SVF, Semantic Verbal Fluency; BNT, Boston Naming Test; RPM, Raven's Progressive Matrices; SDS, Self-Rating Depression Scale; MCl, mild cognitive impairment; AD, Alzheimer's disease; FTD, frontotemporal dementia; DLB, dementia Lewy body; VaD, vascular dementia; ACE, Addenbrooke's Cognitive Examination; CDR, Clinical Dementia Rating Scale; MAAS, Maastricht aging study; CAMCOG, Cambridge Assessment of Mental Disorders in Elderly; GIT, Groninger Intelligence Test; SCWT, Stroop Color Word Test; CST, Concept Shifting Test; MoCA, Montreal Cognitive Assessment; IQCODE, Informant Questionnaire on Cognitive Decline of Elderly; ND, no dementia; ACE-R, Addenbrooke's Cognitive Examination, Revised; TMT, Trail Making Test; SDMT, Symbol Digit Modalities Test; HVLT, Hopkins Verbal Learning Test; GDS, Geriatric Depression Scale; BDI-II, Beck Depression Inventory II. 
insensitive to complex cognitive deficits. All patients in the selected articles were evaluated using the MMSE and other neuropsychological assessments to detect cognitive abnormalities after ischemic stroke.

Bour et $\mathrm{al}^{44}$ and Cao et $\mathrm{al}^{45}$ reported that MMSE alone is inaccurate for the detection of neuropsychological deficits in young people. The authors recommended an MMSE cutoff of 27 for multiple sclerosis. Yoshida et $\mathrm{al}^{46}$ and Raimondi et $\mathrm{al}^{47}$ used Addenbrooke's Cognitive Examination (ACE) with the MMSE to detect early dementia, and the authors showed that ACE was more accurate than MMSE. Dong et $\mathrm{al}^{48}$ and Sikaroodi et $\mathrm{al}^{49}$ found that MoCA was superior to MMSE in detecting early dementia. Pendlebury ${ }^{50}$ found that MoCA and ACE-R exhibited good sensitivity and specificity for $\mathrm{MCI}$, and both were feasible as short tests useful for routine clinical practice.

\section{Discussion}

Stroke is a CVD that can increase the risk for cognitive impairment and lead to dementia. PSD, particularly $\mathrm{VaD}$, may affect up to $21 \%$ of stroke survivors after the third month of stroke onset. This study shows that stroke patient demographics, including age and sex, were associated with cognitive impairment and dementia.

Cognitive impairment increased with age because of the decrease in vessel and cerebral artery inflow. This decrease in cerebral blood flow to the brain may damage the brain and cause cognitive decline. Moreover, the risk factors associated with stroke, including CVD, hypertension, and diabetes mellitus, can be linked to VaD. For example, hypertension can reduce blood flow to the brain, which can lead to $\mathrm{VaD}$ and heart diseases, such as atrial fibrillation. This can also reduce cardiac output leading to cerebral hypoperfusion and myocardial infarction and is associated with cognitive decline.

A heavy smoking habit is also a stroke risk factor that can cause decline in memory function. For instance, Atluri et $\mathrm{al}^{51}$ analyzed the molecular mechanisms behind the increase the risk of human immunodeficiency virus (HIV)-associated neurocognitive disorder in HIV-infected heavy cigarette smokers. Impairment in cognitive function, such as attention, executive function, language, short-term memory, working memory, and visual and verbal memories, could also be associated with VCI spectrum stages.

Several neuropsychological assessments are used to test the mental ability of patients following a stroke diagnosis. The MMSE test is widely used for dementia. However, this test only emphasizes language and constructional items.
The MMSE cannot predict long-term cognitive decline. Researchers have used the MoCA and ACE-R assessments to detect dementia because both exhibit good sensitivity, particularly at the MCI stage.

This study has some limitations. First, only 19 articles were reviewed because studies on $\mathrm{VaD}$ patients, stroke risk factors, and cognitive function within the first 3 months after stroke onset are limited. Moreover, the sample sizes were small and there is a need for additional studies for the early detection and prediction of PSD. Besides, the file drawer problems for all studies in this area of research, many studies may be reviewed but never published, and these studies may have different results from the other studies that have significant findings and are typically published. Despite these drawbacks, this review may provide a means to identify the role of neuropsychological assessments for the early detection of PSD. Finally, cognitive impairments are widely assessed by neuropsychological assessments, but until recently, no specific neuropsychological assessments to evaluate and predict PSD that included memory loss existed.

Future research on the roles of neuropsychological assessments is required to predict and evaluate poststroke $\mathrm{VaD}$, including the evaluation of memory impairment in the early stages. This will reveal subtle changes that might define indicators for the early detection of dementia that will help medical doctors and clinicians in planning and providing a more reliable prediction of the course of the disease. In addition, this will aid in the development of the optimal therapeutic program to provide dementia patients with additional years of a higher quality of life.

\section{Conclusion}

This article reviewed the roles of the available neuropsychological assessments in detecting poststroke cognitive impairment and dementia, as well as the affected domain, within the first 3 months of a stroke diagnosis. No specific assessment was suitable for the whole spectrum of the VCI, but several assessment candidates can be suggested for the early detection of the disease. MMSE, MoCA, and ACE-R were among the most useful assessments that would help in the clinical evaluation of cognitive impairment following a stroke. Given their differences in sensitivity and specificity, these tests can be used together to assess different types of patient demographics and risk factors. Combining several assessment methods for neuropsychological testing will be useful and help health care practitioners to provide a suitable treatment program for and to help avoid the cognitive decline of stroke survivors. 


\section{Disclosure}

The authors report no conflicts of interest in this work.

\section{References}

1. Cumming TB, Marshall RS, Lazar RM. Stroke, cognitive deficits, and rehabilitation: still an incomplete picture. Int J Stroke. 2013;8(1): 38-45.

2. Snaphaan L, de Leeuw FE. Poststroke memory function in nondemented patients: a systematic review on frequency and neuroimaging correlates. Stroke. 2007;38(1):198-203.

3. Morris JC, Storandt M, Miller JP, et al. Mild cognitive impairment represents early-stage Alzheimer disease. Arch Neurol. 2001;58(3): 397-405.

4. Tatemichi TK, Foulkes MA, Mohr JP, et al. Dementia in stroke survivors in the Stroke Data Bank cohort. Prevalence, incidence, risk factors, and computed tomographic findings. Stroke. 1990;21(6):858-866.

5. Leys D, Hénon H, Mackowiak-Cordoliani MA, Pasquier F. Poststroke dementia. Lancet Neurol. 2005;4(11):752-759.

6. Firbank MJ, Burton EJ, Barber R, et al. Medial temporal atrophy rather than white matter hyperintensities predict cognitive decline in stroke survivors. Neurobiol Aging. 2007;28(11):1664-1669.

7. McVeigh C, Passmore P. Vascular dementia: prevention and treatment. Clin Interv Aging. 2006;1(3):229-235.

8. Ankolekar S, Geeganage C, Anderton P, Hogg C, Bath PM. Clinical trials for preventing post stroke cognitive impairment. $J$ Neurol Sci. 2010;299(1-2):168-174.

9. Cumming TB, Marshall RS, Lazar RM. Stroke, cognitive deficits, and rehabilitation: still an incomplete picture. Int J Stroke. 2013;8(1):38-45.

10. Erkinjuntti T, Gauthier S. The concept of vascular cognitive impairment. Front Neurol Neurosci. 2009;24:79-85.

11. Iemolo F, Duro G, Rizzo C, Castiglia L, Hachinski V, Caruso C. Pathophysiology of vascular dementia. Immun Ageing. 2009;6:13.

12. Jacova C, Kertesz A, Blair M, Fisk JD, Feldman HH. Neuropsychological testing and assessment for dementia. Alzheimers Dement. 2007;3(4): 299-317.

13. Desmond DW. Vascular dementia. Clin Neurosci Res. 2004;3(6): 437-448.

14. Korczyn AD, Vakhapova V, Grinberg LT. Vascular dementia. J Neurol Sci. 2012;322(1-2):2-10.

15. O'Brien JT, Erkinjuntti T, Reisberg B, et al. Vascular cognitive impairment. Lancet Neurol. 2003;2(2):89-98.

16. Winblad B, Palmer K, Kivipelto M, et al. Mild cognitive impairmentbeyond controversies, towards a consensus: report of the International Working Group on Mild Cognitive Impairment. J Intern Med. 2004;256(3):240-246.

17. Dauwels J, Vialatte F, Latchoumane C, Jeong J, Cichocki A. EEG synchrony analysis for early diagnosis of Alzheimer's disease: a study with several synchrony measures and EEG data sets. Conf Proc IEEE Eng Med Biol Soc. 2009:2224-2227.

18. Ruitenberg A, Ott A, van Swieten JC, Hofman A, Breteler MM. Incidence of dementia: does gender make a difference? Neurobiol Aging. 2001;22(4):575-580.

19. Snaphaan L, Rijpkema M, van Uden I, Fernández G, de Leeuw FE. Reduced medial temporal lobe functionality in stroke patients: a functional magnetic resonance imaging study. Brain. 2009;132(Pt 7):1882-1888.

20. Planton M, Peiffer S, Albucher JF, et al. Neuropsychological outcome after a first symptomatic ischaemic stroke with 'good recovery'. Eur J Neurol. 2012;19(2):212-219.

21. Werring DJ, Gregoire SM, Cipolotti L. Cerebral microbleeds and vascular cognitive impairment. J Neurol Sci. 2010;299(1-2):131-135.

22. Sheng B, Cheng LF, Law CB, Li HL, Yeung KM, Lau KK. Coexisting cerebral infarction in Alzheimer's disease is associated with fast dementia progression: applying the National Institute for Neurological Disorders and Stroke/Association Internationale pour la Recherche et l'Enseignement en Neurosciences Neuroimaging Criteria in Alzheimer's Disease with Concomitant Cerebral Infarction. J Am Geriatr Soc. 2007;55(6):918-922.
23. American Psychiatric Association. Diagnostic and Statistical Manual of Mental Disorders. 4th ed. Washington, DC: American Psychiatric Association. 1994.

24. Folstein MF, Folstein SE, McHugh PR. "Mini-mental state": a practical method for grading the cognitive state of patients for the clinician. J Psychiatr Res. 1975;12(3):89-98.

25. Smith T, Gildeh N, Holmes C. The Montreal Cognitive Assessment: validity and utility in a memory clinic setting. Can J Psychiatry. 2007; 52(5):329-332.

26. Mathuranath PS, Nestor PJ, Berrios GE, Rakowicz W, Hodges JR. A brief cognitive test battery to differentiate Alzheimer's disease and frontotemporal dementia. Neurology. 2000;55(11):1613-1620.

27. Cedazo-Minguez A, Winblad B. Biomarkers for Alzheimer's disease and other forms of dementia: clinical needs, limitations and future aspects. Exp Gerontol. 2010;45(1):5-14.

28. Hampel H, Frank R, Broich K, et al. Biomarkers for Alzheimer's disease: academic, industry and regulatory perspectives. Nat Rev Drug Discov. 2010;9(7):560-574.

29. Bagnoli S, Failli Y, Piaceri I, et al. Suitability of neuropsychological tests in patients with vascular dementia (VaD). J Neurol Sci. 2012; 322(1-2):41-45.

30. Hughes CP, Berg L, Danziger WL, Coben LA, Martin RL. A new clinical scale for the staging of dementia. Br J Psychiatry. 1982;140: 566-572.

31. Yesavage JA, Brink TL, Rose TL, et al. Development and validation of a geriatric depression screening scale: a preliminary report. J Psychiatr Res. 1982-1983;17(1):37-49.

32. Gorelick PB. Risk factors for vascular dementia and Alzheimer disease. Stroke. 2004;35(11 suppl 1):2620-2622.

33. Tham W, Auchus AP, Thong M, et al. Progression of cognitive impairment after stroke: one year results from a longitudinal study of Singaporean stroke patients. J Neurol Sci. 2002;203-204:49-52.

34. Mok VC, Wong A, Lam WW, Baum LW, Ng HK, Wong L. A casecontrolled study of cognitive progression in Chinese lacunar stroke patients. Clin Neurol Neurosurg. 2008;110(7):649-656.

35. Khedr EM, Hamed SA, El-Shereef HK, et al. Cognitive impairment after cerebrovascular stroke: relationship to vascular risk factors. Neuropsychiatr Dis Treat. 2009;5:103-116.

36. Kandiah N, Wiryasaputra L, Narasimhalu K, et al. Frontal subcortical ischemia is crucial for post stroke cognitive impairment. J Neurol Sci. 2011;309(1-2):92-95.

37. Jaillard A, Naegele B, Trabucco-Miguel S, LeBas JF, Hommel M. Hidden dysfunctioning in subacute stroke. Stroke. 2009;40(7): 2473-2479.

38. Auchus AP, Chen CP, Sodagar SN, Thong M, Sng EC. Single stroke dementia: insights from 12 cases in Singapore. J Neurol Sci. 2002; 203-204:85-89.

39. Stebbins GT, Nyenhuis DL, Wang C, et al. Gray matter atrophy in patients with ischemic stroke with cognitive impairment. Stroke. 2008; 39(3): 785-793.

40. Sachdev PS, Brodaty H, Valenzuela MJ, Lorentz LM, Koschera A. Progression of cognitive impairment in stroke patients. Neurology. 2004;63(9):1618-1623.

41. Graham NL, Emery T, Hodges JR. Distinctive cognitive profiles in Alzheimer's disease and subcortical vascular dementia. J Neurol Neurosurg Psychiatry. 2004;75(1):61-71.

42. Garrett KD, Browndyke JN, Whelihan W, et al. The neuropsychological profile of vascular cognitive impairment - no dementia: comparisons to patients at risk for cerebrovascular disease and vascular dementia. Arch Clin Neuropsychol. 2004;19(6):745-757.

43. Mok VC, Wong A, Lam WW, et al. Cognitive impairment and functional outcome after stroke associated with small vessel disease. $J$ Neurol Neurosurg Psychiatry. 2004;75(4):560-566.

44. Bour A, Rasquin S, Boreas A, Limburg M, Verhey F. How predictive is the MMSE for cognitive performance after stroke? J Neurol. 2010; 257(4):630-637. 
45. Cao M, Ferrari M, Patella R, Marra C, Rasura M. Neuropsychological findings in young-adult stroke patients. Arch Clin Neuropsychol. 2007; 22(2):133-142.

46. Yoshida H, Terada S, Honda H, et al. Validation of Addenbrooke's cognitive examination for detecting early dementia in a Japanese population. Psychiatry Res. 2011;185(1-2):211-214.

47. Raimondi C, Gleichgerrcht E, Richly P, et al. The Spanish version of the Addenbrooke's Cognitive Examination - Revised (ACE-R) in subcortical ischemic vascular dementia. J Neurol Sci. 2012;322(1-2): 228-231.

48. Dong Y, Sharma VK, Chan BP, et al. The Montreal Cognitive Assessment (MoCA) is superior to the Mini-Mental State Examination (MMSE) for the detection of vascular cognitive impairment after acute stroke. J Neurol Sci. 2010;299(1-2):15-18.
49. Sikaroodi H, Yadegari S, Miri SR. Cognitive impairments in patients with cerebrovascular risk factors: a comparison of Mini Mental Status Exam and Montreal Cognitive Assessment. Clin Neurol Neurosurg. 2013;115(8):1276-1280.

50. Pendlebury ST, Mariz J, Bull L, Mehta Z, Rothwell PM. MoCA, ACE-R, and MMSE versus the National Institute of Neurological Disorders and Stroke-Canadian Stroke Network Vascular Cognitive Impairment Harmonization Standards Neuropsychological Battery after TIA and stroke. Stroke. 2012;43(2):464-469.

51. Atluri VS, Pilakka-Kanthikeel S, Samikkannu T, et al. Vorinostat positively regulates synaptic plasticity genes expression and spine density in HIV infected neurons: role of nicotine in progression of HIV-associated neurocognitive disorder. Mol Brain. 2014;7:37.
Neuropsychiatric Disease and Treatment

\section{Publish your work in this journal}

Neuropsychiatric Disease and Treatment is an international, peerreviewed journal of clinical therapeutics and pharmacology focusing on concise rapid reporting of clinical or pre-clinical studies on a range of neuropsychiatric and neurological disorders. This journa is indexed on PubMed Central, the 'PsycINFO' database and CAS,

\section{Dovepress}

and is the official journal of The International Neuropsychiatric Association (INA). The manuscript management system is completely online and includes a very quick and fair peer-review system, which is all easy to use. Visit http://www.dovepress.com/testimonials.php to read real quotes from published authors.

Submit your manuscript here: http://www.dovepress.com/neuropsychiatric-disease-and-treatment-journal 